\title{
Techniques for Mirroring Practice Online
}

\author{
Renay Buchanan and Robert McDougall \\ Central Queensland University, Rockhampton, Australia.
}

\section{r.buchanan@cqu.edu.au r.mcdougall@cqu.edu.au}

\begin{abstract}
In this paper we describe the creative and innovative work that has emerged from the collaboration between content experts and creative designers. The project detailed here focuses on enhancing the current range of online learning opportunities for students studying a level one business mathematics course. We highlight some of the positives and negatives encountered when converting existing print-based materials to quality online educational tools and the mapping of face-to-face instruction into the electronic medium. A discussion of some of the major challenges encountered when creating resources such as these for distribution in an online environment is included. The conference presentation for this work will demonstrate the two primary online resources, worked examples with audio enhancement and simulations.
\end{abstract}

Keywords: Online mathematics education, worked examples, simulation, audio enhancement, Macromedia

\section{Introduction}

The paper will discuss the goals of the project detailing the unique features of both the content area and the aud ience, and examines how the needs of both internal students and students studying at a distance influenced the construction of new course materials and delivery mechanisms.

Buchanan (2002) notes that many of the learning activities that could not be represented by the written word are now possible through technology and multimedia, complementing the assertion (Matuga, 2001) that new pedagogical practices are needed within electronic environments to maximise student learning.

The project sought to uncover computer-based learning (CBL) solutions to recreating the face-to-face tutorial experience that are robust, easily replicated across the discipline (and beyond) and involve communications technologies that are widely accessible and easy to use. Although the targeted delivery method was online, it was equally important that the resources be in a form that could be packaged into an offline medium for convenience and for those areas of Australia, and the world, where Internet access is still very unreliable or extremely costly. The target areas were mathematical processes that are often represented only in completed form when encountered on the printed page and areas that are difficult to discuss over the telephone or by email. Two online resources, simulations and worked examples with audio enhancement, were created to help nurture an understanding of the underlying mathematical principles.

Material published as part of these proceedings, either on-line or in print, is copyrighted by Informing Science. Permission to make digital or paper copy of part or all of these works for personal or classroom use is granted without fee provided that the copies are not made or distributed for profit or commercial advantage AND that copies 1) bear this notice in full and 2) give the full citation on the first page. It is permissible to abstract these works so long as credit is given. To copy in all other cases or to republish or to post on a server or to redistribute to lists requires specific permission from the publisher at Publisher@InformingScience.org

\section{Creating Learning Resources}

Many of the currently accessible online mathematics resources are designed to create tutorial sheets and solutions, from preset groups of que stions, for use in the face-to-face classroom. Online resources which attempt to explain the 


\section{Techniques for Mirroring Practice Online}

processes and algorithms employed to solve problems often offer little more than an electronic version of the printed page although interactive sites are beginning to appear which walk students through a problem. The online simulation resources created as part of this project endeavours to self-pace the students learning by giving them the ability to move forward, and backward through the material at their own speed, whilst exploring each part of the problem and solution. The worked examples attempt to bring a human presence to a mathematical problem by providing commentary by members of the teaching team as each step of the solution unfolds so that the learner is presented with not only the worked solution but also the explanation behind each step.

\section{Developing a Framework for Teaching and Learning}

While there are global parameters that apply to the development of all learning materials, there will always be, in addition, matters connected to the local context that must also be satisfied. These local issues are the focus of this section of the paper.

The lack of general preparedness of academic staff for teaching in an online environment experienced within our institution and the assumptions made by staff about the ability of students learning this way (that is, that academic staff believe students are comfortable in this environment and are probably more knowing of its strengths and weaknesses than they are) are significant issues that must be taken into consideration. A case study by Diana Laurillard (2002) states that "we should be building a body of knowledge of how best to use learning media and creating a teaching profession that knows what it is doing and why". We will explore some of the key elements that were identified as essential to ensure the success of this project.

- The online learning resources should recreate for distance students more of the face-to-face learning environment available to internal students.

Accepting and working from the perspective of what Walker (1993) terms the "deficit model" the aim was to recreate the very rich learning environment a vailable to internal students, which for mathematics tutorials includes: the well-paced demonstration of the solution to key examples illuminating important features; justifying the sequencing of the process; and making students wary of the pitfalls as the y arise. This "community of practice" as referred to by Goos, Galbraith and Renshaw (1994) encourages discussion at all levels, individual reflection and assists students in decoding the formal knowledge. This is a time-honoured activity that should be retained and is now able to be approximated through an online environment for distance students.

- The design of the online learning resources should ensure that the learning activity is as closely connected to the unfolding solution as possible.

Mathematics textbook authors can sometimes struggle with the constraints of the printed page. There is an upper limit to how much space can be devoted to the explanation of an algorithm or mathematical process before the reading material becomes too disconnected from the visual guides, which include illustrative diagrams, graphs and tables. Visual guides to the solution, whose development is an important part of the process, are often only presented in completed form. The reader can end up continually tur ning the page back and forth between the explanation and the focus of the learning activity. The online environment provides an opportunity to maintain this connection without compromising any of the advantages of the detailed explanation. In the following sections of this paper we will detail the resources developed.

In essence the enhancements for the worked examples included an audio commentary similar to that delivered in a tutorial (attached to each solution step) and a head-and-shoulders photograph, which builds a human presence into the learning activity. The creation of the simulations was designed so that the screen has static and dynamic elements that help maintain a focus on the learning task, complementing a 
deconstruction and reconstruction process that allows the solution to be built up from the same starting point the students are presented with in their assignment and tutorial questions. Tait (1994) proposes that for simulations to be an effective resource both an appropriate task and a combination of tutor and learner involvement is required. Although direct tutor and learner involvement is not part of the simulations created they have been designed to mimic this interaction by providing the learner with a step-bystep explanation similar to that which a tutor gives face-to-face.

- The learning style offered by the online learning resources should be closely aligned with those familiar to the student.

This feature of incremental change to the learning style was considered crucial to the success of the project. While staff and students are making the transition to a more online and electronic environment there is a need for as much familiarity with traditional practices as possible to be maintained (including traditional distance education practices). The technology driving an online facility should not be an overwhelming distraction for the learner or the person teaching with the learning tool. Students should not have to develop extensive technological skills not related to the content just so they can utilize the system. A lack of consideration for what Hillman, Willis and Gundawardena (1994) call "learner interface interaction" can result in the technology itself becoming the focus of he learning experience for students.

The format of the traditional worked example is very familiar to students. The enhancement of adding a well-paced commentary and a photograph of the person delivering the commentary takes them from a place they know well, to a richer place where they can still be comfortable whilst partially recreating the atmosphere of mediation by the teacher (Laurillard, 2002). The static areas of the screen built into the simulations allow the student to rely on some information remaining constant so they can concentrate on the dynamic areas of the screen that take the solution forward.

- The online learning resources should be simple and robust in their construction and implementation.

The need for this is clear. In addition to being relatively free of the constraints imposed by commercial packages, requiring a minimum of plug-ins and supportive software, and being reasonably platform and browser independent, the resources should be easy to maintain and operate. Meeting this criteria ensures that staff will need some training to complete low-level trouble shooting when working with students but not so much that it competes with the knowledge needed to understand the concepts presented.

The features of the worked examples with audio have been kept to a minimum with just one design of icon repeatedly performing the same task each time. The simulations have an inbuilt navigation frame containing a number of movement options intuitively labeled. This allows the students to direct their attention to particular areas of the screen with confidence knowing what will be occurring in that space (Allessi \& Trollip, 1991).

- The online learning resources should be easy to replicate.

Developing the skills of academic staff so that they are competent in an online learning environment necessitates that the resources be constructed in such a way so that those at the beginning of this process have confidence that their first exploratory steps into this new teaching and learning methodology will be successful as many are feeling the demands to go online and enrich their resources (Buchanan, 2002). Resource templates were created so that the style could be replicated in other areas of the course, other areas of mathematics, across the pure and applied spectrum and even other discipline areas unrelated to mathematics. 


\section{Techniques for Mirroring Practice Online}

The worked examples with audio are easily adapted to any instructional situation where there is a body of knowledge already available in printed form. More creativity is needed in adapting the simulations to fit new problem areas but the underlying process to create such resources remains consistent.

\section{Worked Examples with Audio Enhancement}

The creation of a series of 18 worked examples accompanied by audio commentary sought to recreate a style similar to that heard in the face-to-face classroom delivery. To add a more personal touch to the learning environment staff were asked to include a head and shoulders photograph of themselves at the top of each of the worked examples in which they are providing the commentary. This enabled the student to not only hear the presenter but to also see the person with whom they were learning. The desired outcome was to foster a sense of belonging for distance students who are not able to attend formal classes and enjoy the interaction between peers and teaching staff.

\section{Design Elements}

Each worked example consists of a single HTML page that is divided into 3 sections (Figure 1). The top (title) section comprises two columns, the thumbnail photograph of the staff member and the title of the worked example. The next (problem) section comprises two columns also. The first column contains the audio icon connected to the introduction and explanation of the mathematical problem and the second column presents the problem in worded form. The last (workings) section contains 3 columns. The first column holds the audio icon connected to the explanation for that step, the second column contains the step number, and the third column contains the working related to that step in the problem.

For each of the worked examples a deliberate attempt was made to keep the total working and viewing area to 8 steps, including the solution. This meant a student had no more then 2 pages to scroll through and with one click could see either the top of the page and the problem, or the bottom of the page and the solution with the minimum of scrolling (TAFE SA, 1998). This was a key design element as the ability to refer constantly to the original problem is important in the learning sequence to enable the reinforcement and importance of each

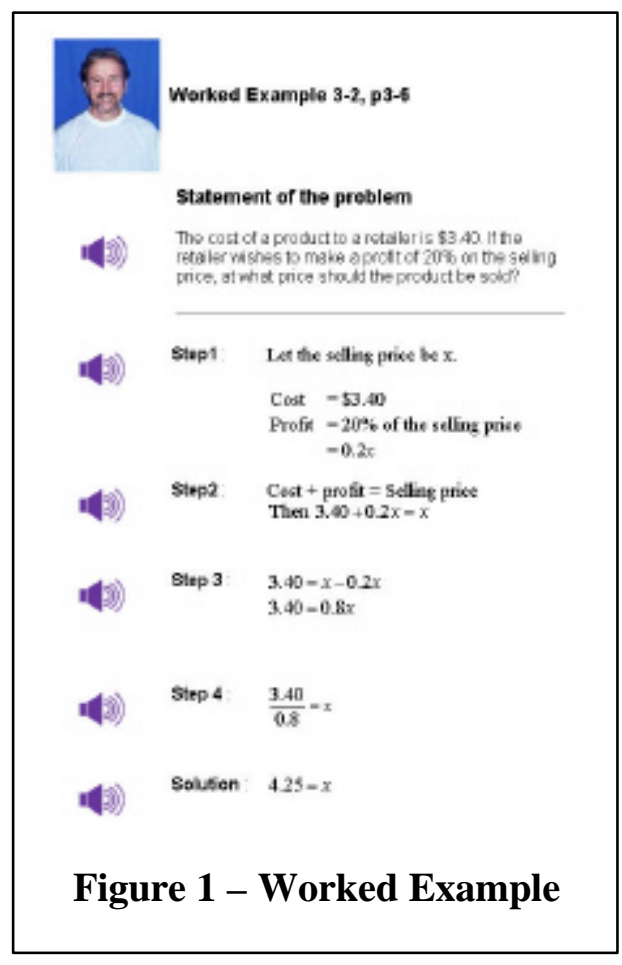
step.

By creating a template consisting of elements in independent blocks each block could be edited ind ividually whilst not affecting the consistency of the overall layout within the one worked example and between different worked examples.

A conscious decision was made to limit the number of different icons and ensure their consistency and familiarity so that a common interface was repeatedly experienced. This meant that the learner was not being distracted by the environment and found predictable actions and resources. Confidence in the environment could then be developed through familiarity and repetition (Allessi \& Trollop, 1991).

\section{Technical Elements}

One of the key criteria that enabled the worked examples to appear seamless was the ability to produce audio commentary without requiring the opening of an audio control window. Many of the students en- 
rolled in this course are not experienced technology users and the added complexity of an audio control window was a feature that was not required and would only clutter the screen and complicate the learning environment unnecessarily.

A search was undertaken to find a way to embed reasonable quality audio into the HTML page without the unwanted consequence of an audio control window. After an inspection of the popular audio players currently on the market proved unsuccessful a more in-depth search was conducted into the new and emerging products appearing on the market.

Through the Crazy Ivan (2001) website a product called Boomer Audio ${ }^{\mathrm{TM}}$ version 3 (at that stage untitled) was found that looked like it would suit our needs. Boomer Audio ${ }^{\mathrm{TM}}$ enabled us to record in MP3 format and convert an audio clip into a Macromedia (1995) Shockwave ${ }^{\mathrm{TM}}$ file with minimal degradation of quality. As the simulations that are also included in the course require Shockwave ${ }^{\mathrm{TM}}$, no additional software needed to be installed on the students' machine. In total Boomer comes as two products Boomer Audio $^{\mathrm{TM}}$ version 3and Boomer Video ${ }^{\mathrm{TM}}$ version 4. Boomer Audio ${ }^{\mathrm{TM}}$ converts audio files (.avi, .wav, .mp3) into Shockwave ${ }^{\mathrm{TM}}$ files using a variety of sampling rates, frames per second, delays, looping, etc with the choice of mono or stereo. Boomer Video ${ }^{\mathrm{TM}}$ can associate an image (.gif, .jpg, .png, .avi) with a Shockwave ${ }^{\mathrm{TM}}$ file allowing you to connect audio and icon together, load it as a movie and associate mouse click functions for play and stop.

Boomer Audio ${ }^{\mathrm{TM}}$ seemed to offer the solution we were looking for, we could convert the MP3 files to Shockwave $^{\mathrm{TM}}$ and use the intrinsic functions of the Dreamweaver ${ }^{\mathrm{TM}}$ version 4 "image behaviours" to add the Shockwave ${ }^{\mathrm{TM}}$ file to the image icon and incorporate a play, pause, stop and rewind actions. Unfort unately this results in some of the problems with regard to the layout and design of the worked examples. A side effect of a call to a Shockw ave ${ }^{\mathrm{TM}}$ file was the reaction of the Internet browser to refresh itself on each call. This resulted in the page jumping back to the top of the HTML document each time an audio icon was clicked. This clearly was an undesirable feature as the student lost the location of the original step and was not able to associate the audio commentary with the step in the problem. Many solutions were trailed including calls to anchors, these were also not successful as there was no way of knowing what position the student had scrolled to on the screen and an inevitable screen jump, even though slight, would still occur.

After trailing many combinations of associated action calls the creator of the conversion software, Harry $\mathrm{M}$ Hayes, found a workable, although not ideal, solution. The solution was to create a Boomer Video ${ }^{\mathrm{TM}}$ that combined both the audio Shockwave ${ }^{\mathrm{TM}}$, the image icon and the associated actions into one Shockwave $^{\mathrm{TM}}$ movie file. The downside of this solution was the requirement to now have one image file for every icon used in the worked examples, and a small movie (call) file for each shockwave audio file. This resulted in approximately an extra 100 files for each movie file and 100 duplicate audio icons in total for the 18 worked examples finally created. Fortunately for our project the shockwave movie files only totalled $2 \mathrm{~KB}$ in size and the audio icon only $1 \mathrm{~KB}$ in size.

An essential requirement of the project was that the resources created be as platform independent as possible. This included browser independent and operating system independent in additional to being webfriendly and downloadable on some of the slowest connections still in use in rural Australia (28K modems). To ensure the download time was reasonable trials were conducted with a selection of the resources using the student modem pool to model and assess a low speed student connection. In conjunction it was felt equally important that students would need to make minimal adjustments to their common operating environment to accommodate and view the resources as the course did not cover any techno logy aspects and students may not have acquired this expertise through previous studies.

The recording process was a new venture for many of the project participants. In consultation with the Video and Audio Production Unit within Central Queensland University general advice and tips on 


\section{Techniques for Mirroring Practice Online}

technique were prepared for the audio commentary. Many of the elements involved in voice-overs are similar to that of writing for radio. Robert O'Sullivan (1992) notes one of the important aspects to be conscious of when writing for a radio audience is the listener in most cases will usually be doing something else while listening. This is precisely what we are trying to achieve in the worked example commentary. It needs to be such that it partners the other activities of the learner and assists in the overall understanding of the concepts presented. Some of the important elements O'Sullivan (1992) gives

\begin{tabular}{|c|c|}
\hline Audio Area & Points of Note \\
\hline \multirow[t]{3}{*}{ Scripting } & $\begin{array}{l}\text { Length - A student's concentration span when only listening to an ex- } \\
\text { planation with no moving interaction should be kept to a maximum of } \\
20-30 \text { seconds. }\end{array}$ \\
\hline & $\begin{array}{l}\text { Repetitiveness - The students do not have a copy of the audio commen- } \\
\text { tary so if there is an especially important point repeat it again in the step } \\
\text { or repeat it as an important factor in the solution commentary. }\end{array}$ \\
\hline & $\begin{array}{l}\text { Consistency of start and finish phrases - allow students to get used to } \\
\text { a personal greeting from each of the audio voices, which enables them } \\
\text { to associate the thumbnail picture of the staff member. Conclude each } \\
\text { problem with a common ending to signify that the solution is complete. }\end{array}$ \\
\hline Voices & $\begin{array}{l}\text { A deliberate decision was made not to go with professional voices but } \\
\text { with the staff that would/could be teaching the students. Again the con- } \\
\text { nection between the learning activity and the expert in the field is an } \\
\text { important factor in trying to foster the sense of belonging in the "ex- } \\
\text { tended" classroom. }\end{array}$ \\
\hline Testing & $\begin{array}{l}\text { A trial of one worked example was conducted to refine our creation and } \\
\text { production steps. This was invaluable as many little things that would } \\
\text { consume a great deal of time if not accounted for before recording time } \\
\text { were uncovered. }\end{array}$ \\
\hline Recording & $\begin{array}{l}\text { It became very evident that repeated tests on the same example were } \\
\text { significantly different when recorded on separate days and at different } \\
\text { times. One of the most important factors of the recording process then } \\
\text { was the ability for the entire process to be started and completed within } \\
\text { one sitting for each person. This way the consistency of tone of voice, } \\
\text { the speed of speaking and the word emphasis was maintained for each } \\
\text { example by the one staff member. There was no necessity to record in } \\
\text { profe ssional sound studios as the quality we were aiming for was not } \\
\text { that of the symphony orchestra but one of small file size and minimal } \\
\text { degradation once converted to MP3 and then Shockwave }{ }^{\mathrm{TM}} \text {. We were } \\
\text { able to utilise a mobile unit to record in different locations so a number } \\
\text { of staff and a variety of voices could be included. }\end{array}$ \\
\hline $\begin{array}{l}\text { Format and } \\
\text { conversion }\end{array}$ & $\begin{array}{l}\text { Taking into consideration the basic equipment students would be using } \\
\text { to listen to the audio, we wanted reasonably good quality sound files for } \\
\text { the initial recording that would allow us to convert to MP3 and then to } \\
\text { Shockwave }{ }^{\mathrm{TM}} \text { without significant degradation in quality and resulting in } \\
\text { small files for use over the Internet. }\end{array}$ \\
\hline
\end{tabular}

Table 1 - Guidelines for developing audio commentary 
attention to directly relate to the creation of commentary for mathematical problems. When applying these guidelines the following important points emerge: the necessity for warm- up words or an introduction to alert the listener and ignite the aural sense; placing names and important details a few words into the lead sentence to ensure they are not missed and attention has not waned; taking care to avoid words that could be misunderstood or acronyms that need interpretation; and ensuring sentence construction is simple, clear and direct.

Table 1 describes a list of the general guidelines we have compiled from our collective experiences in creating voice-overs for mathematical problems. Much of the lessons learnt in this exercise evolved from placing ourselves in the learners' shoes and seeking novice independent testing of the resources.

\section{Simulations for Mathematical Algorithms}

The simulations were created using Macromedia Flash $^{\mathrm{TM}}$ version 5 and are used to depict complex mathematical processes not easily explained by the printed page because of their dynamic nature.

As the use of simulations was completely new to this course an introductory page (Figure 2) was created to introduce students to the concept of a simulation and to give them a basic idea of how to navigate the learning process once inside the simulation. Movie Camera icons were used to depict the presence of a simulation for a concept (see Figure 3). At the outset of the project a simulation was envisaged for each chapter (week) of the course. Once de velopment of the simulations was underway it was realised that the time needed to produce each simulation would pro-

\section{Simulations}

Each the simulations presented below hren you dick on the icon are displayed in a separate window. This allowrs you to wi ex a simulation while also being able to navigate through your webct course. The navigation buttons in the simulations can be found on your bottom barmer of the screen. They consist of:

- Back (to take you back one step in the simulation)

- Next [to move you one step future into the examples

- Start again [this will take you back to the start of the simuation'

and

- Exit (to leave the simulation and retum to this page

Some simulations may also have one additional button

- View Full Solution ithis tikes you to a page that consists of the total working for the example].

Figure 2 - Introducing simulations

hibit the production of a complete suite of simulations and the decision was made in the initial phase to focus on three of the key areas.

\section{Design Elements}

The Navigation tools developed for inclusion in the simulations needed to be intuitive, easily located and simple in their implementation and action. A navigation bar was created along the bottom of the window that allowed students to walk forward and backward through the problem at their own pace. Buttons were turned grey when they were not active so that the student knew there was no "Next" or "Back" screen. Part of the planning for the simulations included the reasoning that students may only have difficulties understanding some sections of a problem. Forcing students to progress linearly through an entire problem may turn them away from using the resource. For this reason we have added to the navigation bar the button "View Full Solution" which allows students to jump to the final slide at any point in the simulation. In conjunction with this we added a "Start again?" button that allowed students to return to the first step at any time to repeat a section of the problem or refer

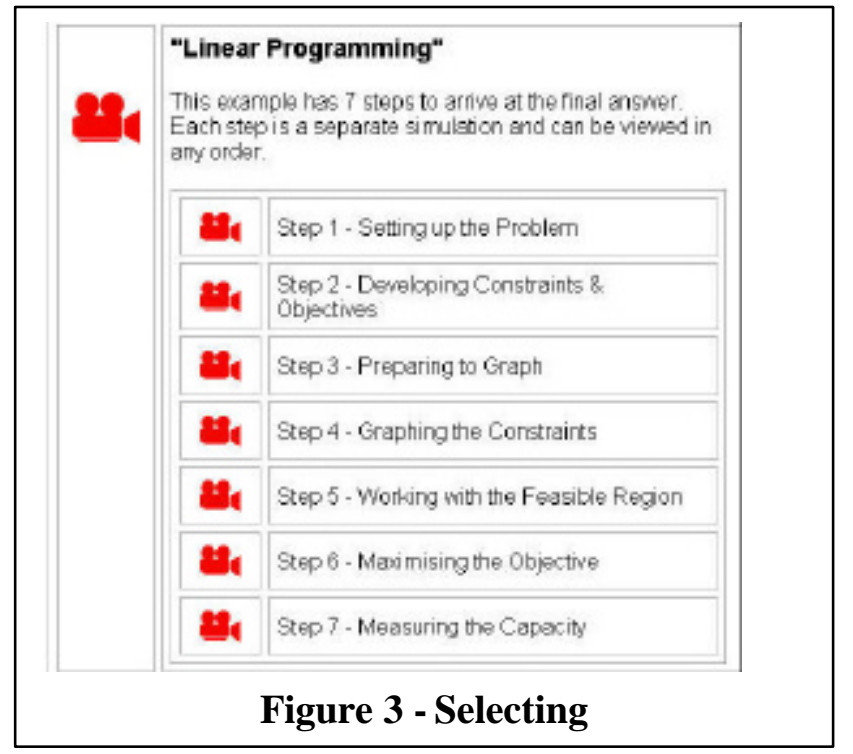




\section{Techniques for Mirroring Practice Online}

to the initial steps once more deeply in the workings. A thought was given to enabling the learner to jump to any step in the solution but this required a more complex navigation system than what was currently being used. The decision was made not to include this function but instead ensure that simulations were kept to a reasonable length so that moving to any part of the solution was not prohibitive. This strategy was used in the third simulation on linear programming where the entire problem and solution has been broken into seven discrete steps (Figure 3).

The screen is divided into three sections and a constant portion of space is allocated to each section for each simulation. The initial target was to keep the portions static for every simulation but this proved to be impractical as each problem and solution required a different amount of problem space and working space. So the compromise was made to retain a constant space allocation within each simulation to maintain a degree of learner focus and predictability. The aim was to maximize the working area for each problem keeping sufficient space to display the problem as static information throughout the unfolding steps of the solution.

To define the static area from the working area so that focus could be directed a separator bar was used. The working area of the screen again comprised two parts - the solution area and the "in class tips" explanation area. The "in class tips" consisted of a limited number of lines that enabled the content expert to add a few words of explanation that would usually accompany the problem when explained during the internal tutorial interaction. The words in this area were shaded grey to differentiate them from the focus of the solution area that can also contain text.

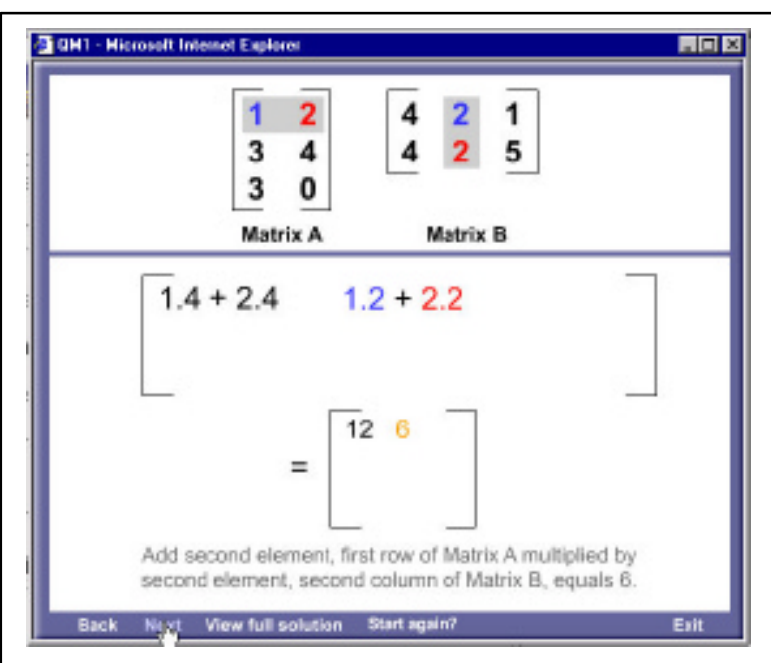

Figure 4 - Matrix multiplication simulation

The solution area is by far the largest portion of the screen and the solution is built up slowly in this workspace. The working area is the only area of the screen in which the material changes from step to step. The solution area undergoes the most change and the "in class tips" support the changes made in generating the solution. In some of the simulations (see Figure 4) the problem section of the screen is highlighted when certain steps are performed which are detailed in the solution area. This enabled the association of the problem and solution and replaced the need for waving arms and pointing mechanisms. In all of the simulations, colours are used to indicate association between elements of the problem and those needed in the solution (Allessi \& Trollop, 1991). When many factors are needed for the solution, like the values for the matrices in Figure 4, different colours were consistently used to differentiate important qualities like position within rows and columns.

\section{Technical Elements}

The simulations were constructed using templates that were built up using layered frames in Flash' ${ }^{\mathrm{TM}}$. Once the template for the entire simulation was completed the content could then be placed into each frame and the solution developed. The process of finalising the template was difficult and time consuming. Storyboards assisted in planning out the content that would be needed for each step. The template started by constructing the screen for the busiest step. The template was then tested on each of the remaining steps to ensure that each step would fit inside that template. In all cases there were many iterations of the template before one size would fit all of the steps within a problem. This was a time consuming but essential process as the screen layout needed to remain static throughout the problem ensuring students were not distracted from the learning activity by shifting focus. The first simulation was the 
longest to construct and the lessons learnt from that development process refined our strategies for the subsequent simulations. A key to much of our development work was the storyboards, which allowed the content expert to set out the required information whist being constrained by the restrictions of a computer screen rather then a handwritten page. This allowed all of the team involved in the development work to understand the challenge of moving from a flowing realtime medium to a static online medium.

The simulations were developed into their final state using Macromedia Flash ${ }^{\mathrm{TM}}$ and Dreamweaver ${ }^{\mathrm{TM}}$. This allowed us to include a link in the introductory page to the free players available through the Macromedia website. The simulations were designed to be easily displayed on a $800 \times 600$ screen without the need to change any of the learners normal display settings. The simulations run both on IBM compatible and MacIntosh computers. The simulations will run under both Netscape and Internet Explorer ve rsions 3.0 or above, regardless of operating system.

All of the mathematical equations and processes displayed in the simulations had to be drawn as a piture in Freehand ${ }^{\mathrm{TM}}$ version 10, saved as an image and inserted into the simulation. This meant that any numerical or layout error in the image required the original Freehand ${ }^{\mathrm{TM}}$ picture to be edited/redrawn, resaved and reinserted. Although this was not a complex process it was a time consuming one and added an additional step where care was needed to ensure that the correct version was inserted.

The overall aim for the simulations was to enable the building up of a solution from the same blank page that the students are presented with and then being able to gradually add information, as appropriate to arrive at a complete worked solution.

\section{Concluding Comments}

The design goal of the worked examples was to enrich the content by providing more of a human presence in the learning environment and to forge closer links between the solution steps and the explanation offered to support them in line with the teaching and learning framework described earlier. The simulations sought to present a more realistic demonstration of the solution process for more complicated and extended mathematical algorithms by allowing solutions to begin where the student must begin (that is, with a blank workspace) and then detailing the construction of the solution step-by-step avoiding the constraints some text book authors must satisfy with the printed page.

The most obvious design development that can evolve from this point onwards is the connection of audio commentary to the simulations - a more straightforward process now that many of the unforseen difficulties have been negotiated by the worked examples. It was a deliberate decision not to link them in the initial phase of the project so that the enhancements did not compete with each other clouding the upcoming evaluation analysis to be impemented.

The initial introduction to the resources is to consist of short slide shows introducing all the staff associated with the course (to be toggled on and off as different staff carry the teaching load for any particular term's offering). These will carry an audio voice-over highlighting that person's values and suggestions for a successful term's study, typical of the introductory material presented to internal students at the beginning of term. Again, slide shows plus audio provides a much more effective outcome over the equivalent video segment when availability of me mory and download speed remain an issue.

Matching project goals with the human potential to achieve such outcomes over an extended time period is a delicate balance when work demands are high. In the process of developing these resources, opportunities arose for better understanding the working environment in the following areas: dealing with team dynamics; team workload issues; multi-skilled personnel communication; shared decision making; distributed geographical locations of team members; and reliance on telecommunications for meetings and prototyping. Many of these challenges were ove rcome by the enthusiasm and willingness of each 


\section{Techniques for Mirroring Practice Online}

team member to realise the pressures under which their co-team members were working and to be flexible to the requirements that the situation demanded.

The technical aspects and complexity of the development of these resources has been conscientiously kept to a minimum so that the task of recreating similar resources in different discipline areas might be a straightforward process. At this time, generic object creation processes which facilitate the timely straightforward development of learning resources is a more attainable goal than that of the more highly developed technique of transferable learning objects.

We believe that any area of student study that involves the simultaneous processes of comprehension and analysis will benefit from such a learning framework. For example, a number of the concepts encountered in introductory programming courses where the program under investigation is presented as a whole, could easily be supported by suitable audio commentary highlighting the various aspects of the program and the way its components mesh together to complete the overall task. For creative work, individual sub-algorithms could be constructed using the simulation approach helping to reshape the idea that programs are written top-down line-by-line. Journalism studies and essay analysis/review in general is another academic process which could benefit from such an approach to online learning.

Future research is needed to evaluate the effectiveness of each aspect of the resources. The questions of what worked, why and why not, are the next step in learning more about the evolving learning process of todays' student.

\section{Acknowledgements}

Fellow academics Ms Margaret Flanders and Ms Sue Lindsay have contributed significantly to the success of this project. The creative and technical support of the Multimedia Development Centre of Central Queensland University have put form to these ideas - thank you to all.

\section{References}

Alessi, S. and Trollip, S. (1991). Computer-based instruction - methods and development, 2nd edn, Prentice-Hall, NJ.

Buchanan, R. (2002). Moving and growing together - delivering education in the new millennium, 2002 Informing Science + IT Education Conference, June 19-21, 2002, Cork, ISSN 1535-07-03.

Crazy Ivan Productions (2001). Boomer audio and video, available at: http://www.gfx2swf.com/ (accessed on September 19, 2002).

Goos, M., Galbraith, P. and Renshaw, P. (1994). Collaboration, Dialogue and Metacognition: The Mathematics Classroom as a Community of Practice in Challenges in Mathematics Education: Constraints on Construction; Proceedings of the Seventeenth Annual Conference of the Mathematics Education Research Group of Australasia (MERGA), Lismore, July 5-8 1994, vol. 1 eds. G. Bell, B. Wright, N. Leeson and J. Geake, pp. 305-313.

Hillman, D., Willis, D. and Gunawardena, C. (1994). Learner-interface interaction in distance education: an extension of contemporary models and strategies for practitioners, American Journal of Distance Education, vol. 8, no. 2, pp. 30-42.

Laurillard, D. (2002) Rethinking University Teaching a conversational framework for the effective use of learning technologies", $2^{\text {nd }}$ edn., Routledge Falmer, London.

Macromedia Technologies (1995-2002). Available at: http://www.macromedia.com/ (accessed on September 19, 2002).

Matuga, J. (2001). Electronic pedagogical practice: the art and science of teaching and learning online, Educational Technology and Society, vol. 4, no. 3, ISSN 1436-4522.

O'Sullivan, R. (1992). An Introduction to Journalism, Study Resources, University of Southern Queensland Press, Australia.

TAFE SA (1998) Pedagogical Issues: ANTA Teaching \& Learning Styles that Facilitate Online Learning, Australian National Training Authority. Available at: http://dino.tafe.sa.edu.au/lsrsc/one/natproj/tal/index.htm, (accessed on 3rd January 2003).

Tait, K. (1994) DISCOURSE: the design and production of simulation-based learning environments, in Design and Production of Multimedia and Simulation-based Learning Material, eds. Ton de Jong and Luigi Sarti, Kluwer Academic Publishers, Dordrecht. 
Walker, R. (1993). Open learning and the media: transformation of education in times of change, in Reforming OPEN AND DISTANCE Education Critical Reflections from Practice, eds. T. Evans and D. Nation, Kogan Page Limited, London, pp. 15-35.

\section{Biography}

Renay Buchanan has been part of the Central Queensland University for the past 12 years in which time her experiences in teaching, tutoring and development of educational materials has lead to a recent secondment to the Division of Teaching and Learning Services (DTLS) - Multimedia Design Centre. In this time the development of the resources described in this paper were developed and following her return to the Faculty of Informatics and Communication within which the course resources were being used collaborated with the primary project leader to write this paper about that experience.

Robert McDougall has worked as an academic at Central Queensland University for more than 15 years. He has played a significant role in the delivery of introductory business mathematics courses for much of this time and been a part of the development team for learning resources through a series of technological advances. While he has integrated a number of Internet applications into his teaching work, this is his first foray into the development of useful online resources. 